Table 1. Siena Myositis Ultrasound Grading Scale (SMUGS).

\begin{tabular}{|c|c|c|c|}
\hline & Grey-scale edema & Grey-scale atrophy & Power Doppler \\
\hline 0 & $\begin{array}{l}\text { Normal muscle echotexture with } \\
\text { hyperechoic septa and } \\
\text { hypoechoic muscle fibers, } \\
\text { conserved thickness. }\end{array}$ & $\begin{array}{l}\text { Normal muscle echotex- } \\
\text { ture, with hyperechoic } \\
\text { septa and hypoechoic } \\
\text { muscle fibers, con- } \\
\text { served thickness. }\end{array}$ & $\begin{array}{l}\text { No PD signal. } \\
\text { C }\end{array}$ \\
\hline 1 & $\begin{array}{l}\text { Focal hypoechoic areas, where septa } \\
\text { are less evident. } \\
\text { Conserved thickness. }\end{array}$ & $\begin{array}{l}\text { Focal heterogeneously } \\
\text { hyperechoic areas, } \\
\text { where septa are } \\
\text { thicker and more } \\
\text { evident, and muscle } \\
\text { fibers are thinner. } \\
\text { Conserved muscle } \\
\text { thickness. }\end{array}$ & $\begin{array}{l}\text { One or two PD signals } \\
\text { in at least one muscle } \\
\text { (PD vascular spots, } \\
\text { small vessels of } \\
\text { homogenous diame- } \\
\text { ters, vessel diameters } \\
\text { approximately not } \\
\text { superior to fibrous } \\
\text { intramuscular septa) }\end{array}$ \\
\hline 2 & $\begin{array}{l}\text { Diffuse and heterogeneous hypo } \\
\text { echogenicity (rectus femoris as } \\
\text { hypoechoic or more than vastus } \\
\text { intermedius), septa diffusely less } \\
\text { evident. Conserved thickness. }\end{array}$ & $\begin{array}{l}\text { Diffuse and } \\
\text { heterogeneously } \\
\text { hyperechoic muscle, } \\
\text { with thicker septa } \\
\text { and thinner muscle } \\
\text { fibers. Conserved } \\
\text { muscle thickness. }\end{array}$ & $\begin{array}{l}\text { More than } 2 \text { PD signals } \\
\text { for each muscle (as } \\
\text { vascular spots, small } \\
\text { vessels of homog- } \\
\text { enous diameters, } \\
\text { vessel diameters } \\
\text { approximately not } \\
\text { superior to fibrous } \\
\text { intramuscular septa). }\end{array}$ \\
\hline 3 & $\begin{array}{l}\text { Diffuse and heterogeneous hypo } \\
\text { echogenicity (rectus femoris as } \\
\text { hypoechoic or more than vastus } \\
\text { intermedius), septa diffusely less } \\
\text { evident. Increased thickness } \\
\text { (rectus femoris became thicker } \\
\text { than vastus intermedius). }\end{array}$ & $\begin{array}{l}\text { Diffuse and heteroge- } \\
\text { neously hypere- } \\
\text { choic muscle, with } \\
\text { thicker septa and } \\
\text { thinner muscle fibers. } \\
\text { Reduced muscle } \\
\text { thickness. }\end{array}$ & $\begin{array}{l}\text { More than } 2 \text { PD signals } \\
\text { for each muscle with } \\
\text { larger diameter of } \\
\text { the vessel (at least } \\
\text { superior to fibrous } \\
\text { intramuscular septa), } \\
\text { or vessels with } \\
\text { different diameters or } \\
\text { branched vessels. }\end{array}$ \\
\hline
\end{tabular}
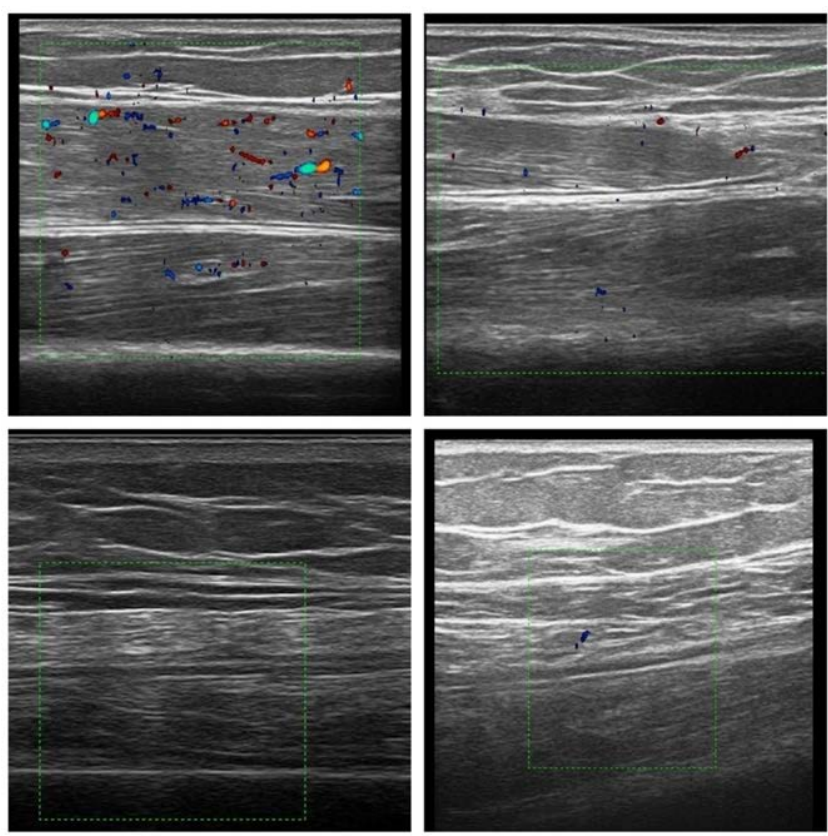

Figure 1. Different PD findings (clockwise) in longitudinal anterior scans of the thigh: $P D 3$ in a patient with a recent diagnosis of anti-Mi2 DM; PD 2 in the same patient after one month of treatment with steroids and Methotrexate; PD 1 in a patient affected by anti-SAE DM, with a suspected disease flare; PD 0 in a patient affected by an advanced polymyositis diagnosed in 2000 , currently not in treatment.

Disclosure of Interests: None declared DOI: 10.1136/annrheumdis-2021-eular.197

\section{POS0833 A RETROSPECTIVE COHORT STUDY IN CHINESE PATIENTS WITH ADULT POLYMYOSITIS AND DERMATOMYOSITIS: RISK OF COMORBIDITIES AND SUBCLASSIFICATION USING MACHINE LEARNING}

J. Zhu' ${ }^{1}$, L. Wu ${ }^{2}$, Y. Zhou ${ }^{3}$, R. Wang ${ }^{1}$, S. Chen ${ }^{1}$, S. Yu ${ }^{4}$, S. Zheng ${ }^{1}$, F. Xiao ${ }^{1}$, J. Li'. ${ }^{1}$ Nanfang Hospital, Southern Medical University, Department of
Rheumatic \& TCM Medical Center, Guangzhou, China; ${ }^{2}$ School of Traditional Chinese Medicine, Southern Medical University, Department of Internal Medicine of Traditional Chinese Medicine, Guangzhou, China; ${ }^{3}$ Guangdong Women and Children Hospital, Department of Obstetrics, Guangzhou, China ${ }^{4}$ Nanfang Hospital, Southern Medical University, Department of Rheumatology, Guangzhou, China

Background: Idiopathic inflammatory myopathy (IIM), also known as myositis, refers to a group of heterogeneous disorders including polymyositis (PM), dermatomyositis (DM), inclusion body myositis and immune-mediated necrotising myopathy. Phenotype, pathogenesis, and prognosis vary due to multi-organ involvement and comorbidities. With the clinical application of MSAs, a new classification system for myositis was explored to reduce confusion between subgroups. But it is far from showing the full picture of myositis due to high heterogeneity. Therefore, it is necessary to systematically evaluate the relevant risk factors of myositis for ILD, other rheumatic diseases, and malignancy for better clinical vigilance. And further exploring the subclassification of myositis is critical Objectives: To identify the risk factors in Chinese patients with adult polymyositis and dermatomyositis for their comorbidities and explore a subclassification system.

Methods: Clinical records of 397 patients with idiopathic inflammatory myopathies were retrospectively reviewed. Logistic regression was used to identify potential risk factors for interstitial lung disease (ILD), other rheumatic diseases, and malignancy after bivariate analysis. Hierarchical clustering and decisiona tree were utilized to identify subgroups and explore a subclassification system. Results: A total of 119 polymyositis and 191 dermatomyositis patients were included. Anti-PM/Scl, anti-Ro52, anti-aminoacyl-tRNA synthetase and antiMDA5 (adjusted odds ratios $(A O R)=4.779,1.917,5.092$ and 7.714 respectively) antibodies were risks $(p<0.05)$, whereas overlapping malignancy was protective ( $A O R=0.107 ; p=0.002$ ) for ILD across polymyositis, dermatomyositis and the total group. In subgroup models, Raynaud's phenomenon, arthralgia and semi-quantitative anti-nuclear antibody $(\mathrm{AOR}=51.233,4.261,3.047$ respectively) were risks for other overlapping rheumatic diseases $(p<0.05)$. For overlapping malignancy, male and anti-TIF1 $\gamma$ antibodies ( $\mathrm{AOR}=2.533,16.949)$ were risks $(p<0.05)$, whereas disease duration and combination of ILD (AOR=0.954, 0.106) were protective in the total group $(p<0.05)$; while anti-NXP2 antibodies were identified as risk factors ( $A O R=73.152 ; p=0.038$ ) in polymyositis. Hierarchical clustering suggested a subclassification with 6 subgroups: malignancy overlapping dermatomyositis, classical dermatomyositis, polymyositis with severe muscle involvement, dermatomyositis with ILD, polymyositis with ILD, and overlapping of myositis with other rheumatic diseases according to the characteristics of grouped patients. Accuracy of the classification and regression trees model was $0.768(95 \% \mathrm{Cl} 0.711$ to 0.819$)$ on training set and $0.633(95 \% \mathrm{Cl} 0.499$ to $0.754)$ on test set.

Conclusion: Accompanying ILD, other rheumatic diseases and malignancy are strongly associated with clinical manifestation and myositis-specific or myositis-associated autoantibodies among Chinese polymyositis and dermatomyositis patients. The subclassification system proposed a more precise phenotype defining toward stratified treatments.

Acknowledgements: The study was supported by the Natural Science Foundation of China [No. 81803932] and the Natural Science Foundation of Guangdong Province [No. 2018030310025 and 2017A030313868]. The funders had no role in study design, data collection and analysis, decision to publish, or preparation of the manuscript

Disclosure of Interests: None declared

DOI: 10.1136/annrheumdis-2021-eular.590

\section{POS0834 LONG-TERM OUTCOME OF SSC ASSOCIATED ILD: IMPROVED SURVIVAL IN PPITREATED PATIENTS}

M. Kreuter ${ }^{1}$, F. Bonella ${ }^{2}$, K. Kathrin ${ }^{3}$, J. Henes ${ }^{4}$, E. Siegert ${ }^{5}$,

G. Riemekasten ${ }^{6}$, N. Blank ${ }^{7}$, C. Pfeiffer ${ }^{8}$, U. Müller-Ladner ${ }^{9}$, A. Kreuter ${ }^{10}$,

P. Korsten ${ }^{11}$, A. Juche ${ }^{12}$, M. Schmalzing ${ }^{13}$, M. Worm ${ }^{14}, I$. Jandova ${ }^{15}$,

L. Susok ${ }^{16}$, T. Schmeiser ${ }^{17}$, C. Guenther ${ }^{18}$, G. Keyszer ${ }^{19}$, J. Ehrchen $^{20}$

A. Ramming ${ }^{21}$, I. Kötter ${ }^{22}$, H. M. Lorenz ${ }^{2}$, P. Moinzadeh ${ }^{23}$, N. Hunzelmann $^{23}$

${ }^{1}$ Center for Interstitial and Rare Lung Diseases, Thoraxclinic, Heidelberg, Germany; ${ }^{2}$ Ruhrlandklinik University Hospital Essen, Center for Interstitial Lung Disease, Essen, Germany; ${ }^{3}$ Faculty of Medicine University of Cologne, Institute of Medical Statistics and Computational Biology, Cologne, Germany; ${ }^{4}$ University Hospital Tuebingen, Rheumatology, Tübingen, Germany; ${ }^{5}$ Charite Universitätsmedizin Berlin, Rheumatology, Berlin, Germany; ${ }^{6}$ University Medical Center UKSH Luebeck, Rheumatology, Lübeck, Germany; ${ }^{7}$ University Hospital Heidelberg, Rheumatology, Heidelberg, Germany; ${ }^{8}$ University Medical Center Ulm, Dermatology, Ulm, Germany; ${ }^{9}$ Kerckhoff Clinic Bad Nauheim, Rheumatology, Bad Nauheim, Germany; ${ }^{10} \mathrm{HELIOS}$ St. Elisabeth Clinic Oberhausen, Dermatology, Oberhausen, Germany; ${ }^{11}$ University Medical Center, Department of Nephrology and Rheumatology, Göttingen, Germany; ${ }^{12}$ Immanuel Hospital Berlin-Buch, Rheumatology, 
Berlin, Germany; ${ }^{13}$ University Hospital Wurzburg, Rheumatology, Würzburg, Germany; ${ }^{14}$ Charite Universitätsmedizin Berlin, Dermatology, Berlin, Germany; ${ }^{15}$ University Hospital Freiburg, Rheumatology, Freiburg, Germany; ${ }^{16}$ St. Josef Hospital Bochum, Dermatology, Bochum, Germany; ${ }^{17}$ Hospital St. Josef Wuppertal, Rheumatology, Wuppertal, Germany; ${ }^{18}$ University Hospital Carl Gustav Carus Dresden, Dermatology, Dresden, Germany; ${ }^{19}$ University Hospital Halle, Rheumatology, Halle, Germany; ${ }^{20}$ University Hospital Muenster, Dermatology, Münster, Germany: ${ }^{21}$ University Hospital Erlangen, Rheumatology, Erlangen, Germany; ${ }^{22}$ Klinikum Bad Bramstedt, Rheumatology, Bad Bramstedt, Germany; ${ }^{23}$ University Hospital Cologne, Dermatology, Cologne, Germany

Background: Gastroesophageal reflux disease (GERD) occurs frequently in patients with systemic sclerosis (SSc) and SSc-associated interstitial lung disease (SSc-ILD). PPI use has to been shown to improve survival in patients with idiopathic pulmonary fibrosis, whereas to date there are no data on the use of PPI in SSc-ILD.

Objectives: This study was aimed to assess whether use of PPI is associated with progression of SSc-ILD and survival.

Methods: We retrospectively analysed 1931 patients with SSc and SSc-ILD from the German Network for Systemic Sclerosis (DNSS) database (2003 onwards). Kaplan-Meier analysis compared overall survival (OS) and progression-free survival (PFS) in patients with vs. without GERD (SSc and SSc-ILD), and PPI vs. no PPI use (SSc-ILD only). Progression was defined as a decrease in either \% predicted forced vital capacity $\geq 10 \%$ or single-breath diffusing capacity for carbon monoxide $\geq 15 \%$, or death

Results: GERD was not associated with decreased OS or PFS in patients with either SSc or SSc-ILD. In patients with SSc-ILD, PPI use was associated with improved OS vs. no PPI use after 1 year $(98.4 \%$ [95\% confidence interval: $97.6-$ 99.3]; $n=760$ vs. $90.8 \%$ [87.9-93.8]; $n=290)$ and after 5 years (91.4\% [89.2-93.8]; $n=357$ vs. $70.9 \%$ [65.2-77.1]; $n=106 ; p<0.0001$ ). PPI use was also associated with improved PFS vs. no PPI use after 1 year $(95.9 \%$ [94.6-97.3]; $n=745$ vs. $86.4 \%$ [82.9-90.1]; $n=278)$ and after 5 years $(66.8 \%$ [63.0-70.8]; $n=286$ vs. $45.9 \%$ [39.6-53.2]; $n=69 ; p<0.0001$ ).

Conclusion: GERD had no effect on survival in SSc or SSc-ILD. PPIs improved survival in patients with SSc-ILD; however, controlled, prospective trials are needed to confirm this finding.

Disclosure of Interests: Michael Kreuter Speakers bureau: Boehringer, Consultant of: Boehringer, Grant/research support from: Boehringer, Francesco Bonella Speakers bureau: Boehringer, Roche, GSK, Consultant of: Boehringer, Roche, GSK, Grant/research support from: Boehringer, Kuhr Kathrin: None declared, Jörg Henes Speakers bureau: Abbvie, Boehringer, Chugai, Roche, Janssen, Novartis, SOBI, Pfizer and UCB, Consultant of: Boehringer, Celgene, Chugai, Roche, Janssen, Novartis, SOBI, Grant/research support from: Chugai, Roche, Janssen, Novartis, SOBI, Pfizer, Elise Siegert: None declared, Gabriela Riemekasten Speakers bureau: Novartis, Janssen, Roche, GSK, Boehringer, Consultant of: Janssen, Actelion, Boehringer, Norbert Blank Consultant of: Sobi, Novartis, Roche, UCB, MSD, Pfizer, Actelion, Abbvie, Boehringer, Grant/research support from: Novartis, Sobi, Christiane Pfeiffer: None declared, Ulf Müller-Ladner: None declared, Alexander Kreuter Speakers bureau: MSD, Boehringer, InfectoPharm, Paid instructor for: MSD, PETER KORSTEN Consultant of: Glaxo, Abbvie, Pfizer, BMS, Chugai, Sanofi, Lilly, Boehringer, Novartis, Grant/research support from: Glaxo, Aaron Juche: None declared, Marc Schmalzing Speakers bureau: Chugai Roche, Boehringer, Celgene, Medac, UCB, Paid instructor for: Novartis, Abbvie, Astra Zeneca, Chugai Roche, Janssen, Consultant of: Chugai Roche, Hexal Sandoz, Gilead, Abbvie, Janssen, Boehringer, Margitta Worm Speakers bureau: Boehringer, Ilona Jandova Speakers bureau: Boehringer, Novartis, Abbvie, Laura Susok Speakers bureau: MSD, Novartis, BMS, Sunpharma, Consultant of: MSD, Tim Schmeiser Consultant of: Abbvie, Boehringer, Novartis, UCB, Claudia Guenther Paid instructor for: Advisory Board Boehringer January 2020, Employee of: Novartis 2002-2005, Gernot Keyszer Consultant of: Boehringer, Jan Ehrchen Speakers bureau: Boehringer, Janssen, Chugai, Sobi, Employee of: Pfizer, Actelion (now Janssen), Andreas Ramming Speakers bureau: Boehringer, Gilead, Janssen, Pfizer, Roche, Consultant of: Boehringer, Pfizer, Grant/research support from: Novartis, Pfizer, Ina Kötter Speakers bureau: several companies, Consultant of: several companies, Grant/research support from: several companies, Hanns-Martin Lorenz Speakers bureau: Abbvie, Astra Zeneca, Actelion, Alexion Amgen, Bayer Vital, Baxter, Biogen, Boehringer, BMS, Celgene, Fresenius, Genzyme, GSK, Gilead, Hexal, Janssen, Lilly, Medac, MSD, Mundipharm, Mylan, Novartis, Octapharm, Pfizer, Roche Chugai, Sandoz, Sanofi, Shire SOBI, Thermo Fischer, UCB, Grant/research support from: basic research studies: Pfizer, Novartis, Abbvie, Gilead, Lilly, MSD, Roche Chugai, Pia Moinzadeh Speakers bureau: Boehringer, Actelion, Grant/research support from:
Actelion, Nicolas Hunzelmann Speakers bureau: Boehringer Janssen, Roche, Sanofi, Consultant of: Boehringer DOI: 10.1136/annrheumdis-2021-eular.878

\section{\begin{tabular}{|l|l}
\hline POS0835 & DECLINE IN FORCED VITAL CAPACITY (FVC)
\end{tabular} IN SUBJECTS WITH SYSTEMIC SCLEROSIS- ASSOCIATED INTERSTITIAL LUNG DISEASE (SSC- ILD) IN THE SENSCIS TRIAL VERSUS HYPOTHETICAL REFERENCE SUBJECTS WITHOUT LUNG DISEASE}

T. Maher $^{1,2,3}$, A. Bourdin ${ }^{4,5}$, E. Volkmann ${ }^{6}$, S. Vettori ${ }^{7}$, J. H. W. Distler ${ }^{8}$, M. Alves ${ }^{9}$, C. Stock ${ }^{10}$, O. Distler ${ }^{11}$ on behalf of the SENSCIS investigators.. ${ }^{1}$ Imperial College London, National Heart and Lung Institute, London, United Kingdom; ${ }^{2}$ Royal Brompton Hospital, National Institute for Health Research Clinical Research Facility, London, United Kingdom; ${ }^{3}$ University of Southern California, Keck School of Medicine, Los Angeles, United States of America; ${ }^{4}$ University of Montpellier, PhyMedExp, Montpellier, France; ${ }^{5}$ University of Montpellier, CHU Montpellier, Department of Respiratory Diseases, Montpellier, France; ${ }^{6}$ University of California, David Geffen School of Medicine, Department of Medicine, Division of Rheumatology, Los Angeles, United States of America; ${ }^{7}$ Ospedale Monaldi, UOC di Fisiopatologia e Riabilitazione Respiratoria, Napoli, Italy; ${ }^{8}$ Friedrich-Alexander-University Erlangen-Nürnberg (FAU), Universitätsklinikum Erlangen, Department of Internal Medicine 3-Rheumatology and Immunology, Erlangen, Germany; ${ }^{9}$ Boehringer Ingelheim International GmbH, TA Inflammation Med, Ingelheim, Germany; ${ }^{10}$ Boehringer Ingelheim Pharma GmbH \& Co. KG, Biostatistics + Data Sciences, Ingelheim am Rhein, Germany; ${ }^{11}$ University Hospital Zurich, University of Zurich, Department of Rheumatology, Zurich, Switzerland

Background: In the randomized SENSCIS trial in subjects with SSc-ILD, nintedanib reduced the rate of decline in FVC over 52 weeks (mL/year) by $44 \%$ compared to placebo. Healthy individuals have varied FVC depending on age, sex, ethnicity and height; expected values can be determined using internationally recognised reference equations.

Objectives: To provide further context to the FVC declines observed in the SENSCIS trial, we compared the decline in FVC observed in subjects with SSc-ILD in the SENSCIS trial with the decline in FVC that would be expected in hypothetical subjects without ILD matched for age, sex, ethnicity and height.

Methods: The SENSCIS trial enrolled subjects with SSc-ILD aged $\geq 18$ years with first non-Raynaud symptom $\leq 7$ years before screening, extent of fibrotic ILD $\geq 10 \%$ on HRCT, FVC $\geq 40 \%$ predicted and DLco $30-89 \%$ predicted. Baseline FVC $(\mathrm{mL})$ and changes in FVC $(\mathrm{mL})$ at week 52 were assessed in the nintedanib and placebo groups, with missing values at week 52 imputed using predictions from the primary analysis model (random slope and intercept model). Changes in FVC in the SENSCIS trial were compared to values in hypothetical healthy reference subjects matched to the SENSCIS subjects for age, sex, ethnicity and height. FVC values in these healthy reference subjects were derived from the equations published by the European Respiratory Society Global Lung Function Initiative in 2012, which were derived from data from over 70,000 subjects. ${ }^{1}$

Results: In the nintedanib and placebo groups of the SENSCIS trial, respectively, mean (SD) time since onset of first non-Raynaud symptom was 3.5 (1.6) and 3.5 (1.8) years. In the nintedanib group, mean (SD) FVC at baseline was 2460 (737) $\mathrm{mL}$, compared with $3403(787) \mathrm{mL}$ in the healthy reference subjects. In the placebo group, mean (SD) FVC at baseline was 2544 (817) $\mathrm{mL}$ compared with $3516(887) \mathrm{mL}$ in the healthy reference subjects. The difference in the change from baseline in FVC at week 52 between the nintedanib-treated subjects in the SENSCIS trial $(n=287)$ and the healthy reference subjects was $26.6 \mathrm{~mL}$ ([95\% Cl: 1.2, 52.0]; $\mathrm{p}=0.04$ ). The difference in the change from baseline in FVC at week 52 between the placebo-treated subjects in the SENSCIS trial $(n=286)$ and the reference subjects was $77.5 \mathrm{~mL}$ ([95\% Cl: 51.4, 103.7]; $p<0.001)$ (Figure 1).

Conclusion: Subjects with SSc-ILD who participated in the SENSCIS trial had marked lung function impairment at baseline compared with healthy matched reference subjects, despite a mean duration of SSc of 3.5 years. Over 52 weeks, the decline in FVC in subjects with SSc-ILD who received placebo was 4-fold greater than in healthy reference subjects. Subjects with SSc-ILD who were treated with nintedanib had a decline in FVC that was only slightly greater than the decline observed in the matched healthy subjects. These data support the clinical relevance of the reduction in the rate of FVC decline provided by nintedanib in patients with SSc-ILD.

\section{REFERENCES:}

[1] Quanjer et al. Eur Respir J 2012;40:1324-43.

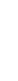

(1)

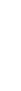

. 